\title{
Research of Executives' Perceptions in Companies and Organizations on the Importance of Mentoring in the Frame of In-house Education and Training
}

\author{
Dr. Iosif Fragoulis \\ As. Professor, School of Pedagogical and Technological Education \\ Tutor, Hellenic Open University, Patra-Greece \\ Tel: 0030-2610-910066_E-mail:sfaka@otenet.gr \\ Dr. Efthymios Valkanos \\ As. Professor, University of Macedonia \\ Tutor, Hellenic Open University, Patra-Greece \\ Tel: 0030-2310-891385Ｅ-mail: evalkan@uom.gr \\ M.Sc. Florou Voula \\ HR Training \& Development, Consultant, Athens-Greece \\ Tel: 0030-210-8028037Ｅ-mail:voula@floroueducation.gr
}

Received: January 21, 2011 Accepted: February 21, 2011 doi:10.5539/ies.v4n3p109

\begin{abstract}
The purpose of the present paper is to present the outcomes of a research on the executives' perceptions in companies and organizations on the importance of mentoring in the frame of in-house education and training.

The paper researches the perceptions of people who work for companies and organizations as far as their participation in mentoring processes is concerned. It also researches mentors' perceptions and the corporate benefits of the use of a mentoring process.

It resulted that the benefits arising from the use of mentoring processes are important for the people working for the companies, for the mentors, as well as for companies and organizations.

The value of the research focuses on the possibilities of the use of mentoring processes in the frame of in-house education and training.
\end{abstract}

Keywords: Corporate executives, In-house education and training, Mentoring, Mentor, Mentee

\section{Introduction}

The meaning of mentoring has its origin in the Greek mythology. It is met for the first time in Homer's "Odyssey", where Mentor guides and educates Telemachus, the son of Odysseus.

Nowadays mentoring constitutes an important tool in human resources education and development. It is focused on the relationship between mentor, an experienced executive and trainee. The first one supports the second in his work, providing advice, guidance and acting as a "model" (Cunningham and Eberle, 1993. Kefalas, 2005:2. Equal, 2006:22).

According to Clawson (1996), the term mentoring has been recently used widely in a great number of discussions and scientific papers and there is a great difficulty in defining its meaning. It is met as a synonym of teaching, coaching or counseling. We may claim that mentoring includes teaching, exceeding the transmission of knowledge and the acquisition of skills (Clawson, 1996:9). It incorporates elements of coaching and counseling within a corporate environment. 


\section{Mentoring as a Tool of Human Resourses Development}

The use of mentoring as a tool in human resources development is very popular among HR development specialists (Van Emmerik, Baugh, and Euwema, 2005:319). The effectiveness of this tool depends mainly on mentors' skills and it is, thus, extremely important to determine mentors' profile.

The increasing demand for mentoring in a corporate environment results from the growth of in-house training programs. Moreover, the corporate interest on mentoring processes results from the decrease of training expenses as well as from the internationally increased tendency for continuing vocational training by experienced personnel (Newton, 2002 in Billet, 2003: 105).

Kram and Hall (1989 cited in Siegel, 2000: 243) present the way mentoring helps individuals to face the organizational changes and to adapt effectively to those changes that require a different learning process than the one existed before change. This constitutes a continuing process that requires the acquisition of new skills and additional ideas useful for the corporate environment.

Broadbent and Papadopoulos, (2009) explain that via mentoring, mentees are encouraged to create an action plan, to think ways of gaining access to information and to transform what they have learned into an alternative action plan (Broadbent \& Papadopoulos, 2009: 324).

\section{The Mentor - Mentee Relationship in a Corporate Environment}

Corporate executives are in a position to have an important part as mentors. This is based on certain key-factors that may influence the development of a mentoring relationship. These factors are the following (Linney, 1999, cited in Todd, 2005:5):

- being able to recognize the employees' needs (eg. for support and guidance) and offer them opportunities that help them stand on their knees and express their weaknesses.

- having common goals with the individuals working in their team.

Corporate executives research the problem, the options and take precautions. Then they focus and prepare their intervention covering the following parameters (Hale, 2003: 51):

\section{i. Situation \\ ii. Action \\ iii. Training \\ iv. Applications}

According to Clutterbuck, (2004), each mentoring relationship functions within a frame. For official mentoring this frame includes culture and/or corporate climate, structure and goal of the action plan, mentor's and mentee's background.

\section{Figure 1. The Context of Mentoring (Clutterbuck, 2004:15)}

Each mentoring pair brings in the relationship expectations related to the aim of the relationship, the role and the behaviors that should be adopted as well as the outcomes. Many of these expectations will be influenced by the frame. The interaction between mentor and mentee is an auto-reinforced system where the behavior of one person influences the behavior of the other. The results have to be positive for both sides in order to have a mentoring relationship that lasts for a long time.

According to Megginson, (2000 cited in Kent, Dennis and Tanton, 2003: 442), a successful mentor creates successful results by helping individuals to stand on their own knees, to find solutions and to achieve their goals. It is essential for a person that wants to become an effective mentor to have demonstrate skills and competences such as: communication and collaboration skills, problem solving and organizational skills as well as skills necessary to assess results (Cunningham and Eberle, 1993:55). Informal corporate mentoring relationships are developed by mutual choice: mentors choose their protégés and they see them as a modern version of themselves, whereas protégés choose for mentors those people who act as models for them. This reciprocal choice contributes to the mentoring relationship which is often characterized as close and intimate (Kram, 1985 cited in Ragins, Cotton, and Miller, 2000:1179).

On the contrary, formal mentoring relationships are usually developed after the assumption of roles is given by a third individual. In many cases, mentor and protégée have not met each other before their first communication (Murray, 1991 cited in Ragins, Cotton, and Miller, 2000:1179).

Kram (cited in Allen and Eby, 2007:6) supports that a quality mentoring relationship is evolved through four stages: 
i. Initiation stage: In this stage both mentor and mentee seek information for each other regarding their professional field.

ii. Cultivation stage: In the stage mentee grows by acquiring knowledge, through the opportunities created by the mentor who also provides support and comfort.

iii. Separation stage: In the stage mentee becomes a more autonomous entity and thanks to this change in the relationship, a disconnection follows.

iv. Redefinition stage: In this stage the end of the mentoring relationship takes place or the relationship is transformed into a friendlier one that does not have an official form.

\section{Method}

\subsection{Research Aim}

The aim of the present work is to research the executives' perceptions in companies and organizations on the importance of mentoring in the frame of in-house education and training.

\subsection{Research Questions}

i. Perceptions of people working for companies and organizations, as far as the mentee's benefit from a mentoring process is concerned, depend on their demographic characteristics.

ii. Perceptions of people working for companies and organizations, as far as the mentor's benefit from a mentoring process is concerned, depend on their demographic characteristics.

iii. Perceptions of people working for companies and organizations, as far as the company's benefit from the use of mentoring processes is concerned, depend on their demographic characteristics.

iv. Perceptions of people working for companies and organizations, as far as their training within a mentoring process is concerned, depend on their demographic characteristics.

\subsection{Sample Description}

The sample of our research consisted of 68 subjects working for Insurance Companies in Attica Region.

\subsection{Data Collection Tools}

The questionnaire was used as the data collection tool, as it allows the collection of many data in short time. This would be extremely time-consuming and difficult with any other technique, due to the great number of insurance units in combination with the researchers' time and means of transportation (Kvale, 1996: 104. Dimitropoulos, 2001:210. Robson, 2002:271).

\subsection{Statistical Process}

Questionnaires were elaborated by the use of the statistical program (SPSS V.17), which is widely used in social sciences. By using this statistical program (SPSS V.17) we analyzed the questions of each questionnaire.

\section{Data Analysis and Results}

\subsection{Demographic Characteristics}

Concerning the demographic characteristics of the individuals that participated in the research, the sample distribution was as following:

Sex:

17 subjects $(25,0 \%)$ were men and $51(75,0 \%)$ were women.

Age:

17 subjects $(25,0 \%)$ were $25-35$ years old, 34 (50,0\%) were 36-45 years old and $17(25,0 \%)$ were 46-55. (Table 1 . Age distribution)

Years working for the same company:

34 subjects $(50,0 \%)$ were working for the same company 1-10 years, 17 (25,0\%) were working 11-20 years and 17 $(25,0 \%)$ had 21-30 years of service.

\section{Position:}

34 subjects (50,0\%) were Unit managers of insurance advisors, 17 (25\%) were Agency managers, Head of an Insurance Office and (25\%) were Insurance advisors. (Table 2. Position distribution)

\section{Education:}


Among the research participants, $40(58,8 \%)$ were University graduates in Economics, 12 (17,6\%) were University graduates in Social Sciences and $16(23,6 \%)$ were University graduates in other Sciences.

Post-graduate studies:

14 participants $(20,6 \%)$ had a Master's degree, while 54 (79,4\%) had not.

\subsection{Perceptions Concerning Mentees' Benefits from a Mentoring Process}

In regard to the answers to the question "Does your participation in a mentoring process contribute to the learning opportunities provided in a protected environment?" the results of the one-variable analysis showed the following: 19 subjects $(27,9 \%)$ answered "extremely", 17 subjects $(25,0 \%)$ answered "very much", while "enough" and "a little" were answers given by 32 subjects $(47,1 \%)$.

The two-variable analysis and the check of $x^{2}$ criterion showed significant statistical differences $(\mathrm{a}<0,05)$ among the subjects' answers regarding their sex $(p=0,001)$, age $(p=0,002)$ and the years of service $(p=0,000)$. (Table 3 . Mentoring and learning opportunities provided in a protected environment )

In regard to the answers to the question "Does your participation in a mentoring process contribute to the development of skills and competences?" the results of the one-variable analysis showed the following: 22 subjects $(32,4 \%)$ answered "extremely", 26 subjects $(38,2 \%)$ answered "very much", while "enough" were the answer given by 20 subjects $(29,4 \%)$.

The two-variable analysis and the check of $x^{2}$ criterion showed significant statistical differences $(a<0,05)$ among the subjects' answers regarding their sex $(\mathrm{p}=0,001)$, the years of service $(\mathrm{p}=0,001)$ and position in the company $(\mathrm{p}=0,001)$.

In regard to the answers to the question "Does your participation in a mentoring process contribute to problem solving in the company?" the results of the one-variable analysis showed the following: 14 subjects (20,6\%) answered "extremely", 32 subjects $(47,1 \%)$ answered "very much", while "enough" and "a little" were answers given by 22 subjects $(32,4 \%)$. (Table 4 . Mentoring and problem solving in the company)

In regard to the answers to the question "Does your participation in a mentoring process contribute to the guidance provided to you by "a significant other" in the company environment?" the results of the one-variable analysis showed the following: 17 subjects $(25,0 \%)$ answered "extremely", 28 subjects $(41,2 \%)$ answered "very much", while "enough" was the answer given by $23(33,8 \%)$.

The two-variable analysis and the check of $x^{2}$ criterion showed significant statistical differences $(a<0,05)$ among the subjects' answers regarding the years of service in the company $(\mathrm{p}=0,001)$ and the position in the company $(\mathrm{p}=0,002)$. (Table 5 . Mentoring and development of a guidance process by an "important other")

\subsection{Perceptions Regarding Mentor's Benefits from a Mentoring Process}

In regard to the answers to the question "Are mentor's communication and cooperation skills improved by his participation in a mentoring process?" the results of the one-variable analysis showed the following: 40 subjects $(58,8 \%)$ answered "extremely", 14 subjects $(20,6 \%)$ answered "very much", while "enough" was the answer given by $14(20,6 \%)$.

The two-variable analysis and the check of $x^{2}$ criterion showed significant statistical differences $(\mathrm{a}<0,05)$ among the subjects' answers regarding their sex $(p=0,001)$, age $(p=0,02)$, years of service in the company $(p=0,000)$ and the position in the company $(\mathrm{p}=0,001)$. (Table 6 . Development of communication and cooperation skills)

In regard to the answers to the question "Is a mentor's position in the company reinforced by his participation in a mentoring process?" the results of the one-variable analysis showed the following: 28 subjects $(41,2 \%)$ answered "extremely", 16 subjects $(23,5 \%)$ answered "very much", while "enough" was the answer given by $24(35,3 \%)$.

The two-variable analysis and the check of $x^{2}$ criterion showed significant statistical differences $(\mathrm{a}<0,05)$ among the subjects' answers regarding their sex $(\mathrm{p}=0,002)$, years of service in the company $(\mathrm{p}=0,01)$ and their position in the company $(\mathrm{p}=0,001)$.

In regard to the answers to the question "Does a mentor get professional satisfaction by his participation in a mentoring process?" the results of the one-variable analysis showed the following: 37 subjects $(54,4 \%)$ answered "extremely", 11 subjects (16,2\%) answered "very much", while "enough" was the answer given by $20(29,4 \%)$. (Table 7. Development of professional satisfaction)

In regard to the answers to the question "Does a mentor experience as sense of contribution to the company in the frame of his participation in a mentoring process?" the results of the one-variable analysis showed the following: 
32 subjects $(47,1 \%)$ answered "extremely", 15 subjects (22\%) answered "very much", while "enough" was the answer given by $21(30,9 \%)$.

The two-variable analysis and the check of $x^{2}$ criterion showed significant statistical differences $(\mathrm{a}<0,05)$ among the subjects' answers regarding their $\operatorname{sex}(\mathrm{p}=0,002)$ and the years of service in the company $(\mathrm{p}=0,000)$.

In regard to the answers to the question "Regarding the training methods and techniques a mentor uses in a mentoring process, are mentor's initial perceptions of them transformed by his participation in the mentoring process?" the results of the one-variable analysis showed the following: 13 subjects $(19,1 \%)$ answered "extremely", 25 subjects $(36,8 \%)$ answered "very much", while "enough" was the answer given by $30(44,1 \%)$. (Table 8 . Development of transformational learning processes within the frame of the mentoring process)

\subsection{Perceptions Regarding the Company's Benefits from the Mentoring Process}

In regard to the answers to the question "Does mentoring process contribute to the development of equal and cooperative relationships among the people working for the company?" the results of the one-variable analysis showed the following: 27 subjects $(39,7 \%)$ answered "extremely", 22 subjects $(32,4 \%)$ answered "very much", while "enough" was the answer given by $19(27,9 \%)$.

The two-variable analysis and the check of $x^{2}$ criterion showed significant statistical differences $(a<0,05)$ among the subjects' answers regarding their sex $(\mathrm{p}=0,000)$, age $(\mathrm{p}=0,01)$ and the years of service in the company $(\mathrm{p}=0,001)$.

In regard to the answers to the question "Does mentoring process contribute to the best use of the company's human resources?" the results of the one-variable analysis showed the following: 11 subjects $(16,2 \%)$ answered "extremely", 27 subjects (39,7\%) answered "very much", while "enough" was the answer given by $30(44,1 \%)$.

The two-variable analysis and the check of $x^{2}$ criterion showed significant statistical differences $(\mathrm{a}<0,05)$ among the subjects' answers regarding their sex $(\mathrm{p}=0,001)$ and the years of service in the company $(\mathrm{p}=0,02)$. (Table 9 . Contribution of mentoring to the best use of the company's human resources)

In regard to the answers to the question "Does mentoring process support the company's innovations?" the results of the one-variable analysis showed the following: 17 subjects $(25,0 \%)$ answered "extremely", 28 subjects $(41,2 \%)$ answered "very much", while "enough" was the answer given by $23(33,8 \%)$.

The two-variable analysis and the check of $x^{2}$ criterion showed significant statistical differences $(\mathrm{a}<0,05)$ among the subjects' answers regarding their sex $(\mathrm{p}=0,000)$, age $(\mathrm{p}=0,002)$ and the years of service in the company $(\mathrm{p}=0,001)$. (Table 10. Contribution of mentoring to company innovations)

In regard to the answers to the question "Does mentoring process contribute to the company's goal achievement?" the results of the one-variable analysis showed the following: 17 subjects $(25,0 \%)$ answered "extremely", 33 subjects (48,5\%) answered "very much", while "enough" was the answer given by 18 (26,5\%).

The two-variable analysis and the check of $x^{2}$ criterion showed significant statistical differences $(\mathrm{a}<0,05)$ among the subjects' answers regarding the years of service in the company $(\mathrm{p}=0,001)$ and their position in the company $(\mathrm{p}=0,000)$.

In regard to the answers to the question "Does mentoring process support the company's viable development?" the results of the one-variable analysis showed the following: 27 subjects (39,7\%) answered "extremely", 22 subjects $(32,4 \%)$ answered "very much", while "enough" was the answer given by $19(27,9 \%)$.

The two-variable analysis and the check of $x^{2}$ criterion showed significant statistical differences $(\mathrm{a}<0,05)$ among the subjects' answers regarding their sex $(\mathrm{p}=0,001)$, age $(\mathrm{p}=0,001)$ and the years of service in the company $(\mathrm{p}=0,000)$. (Table 11. Contribution of mentoring to the viable development of the company)

\subsection{Perceptions Regarding Vocational Training in the Frame of the Mentoring Process}

In regard to the answers to the question "Do you think it is necessary to be trained on mentoring issues?" the results of the one-variable analysis showed the following: 26 subjects $(38,2 \%)$ answered "extremely", 24 subjects $(35,3 \%)$ answered "very much", while "enough" was the answer given by 18 (26,5\%).

The two-variable analysis and the check of $x^{2}$ criterion showed significant statistical differences $(\mathrm{a}<0,05)$ among the subjects' answers regarding their sex $(\mathrm{p}=0,001)$, age $(\mathrm{p}=0,00)$ and the years of service in the company $(\mathrm{p}=0,002)$. (Table 12. Necessity of training on mentoring issues)

In regard to the answers to the question "Do you prefer your vocational training on mentoring to take place traditionally - face to face and by using modern - distance learning methods?" the results of the one-variable analysis showed the following: 27 subjects $(39,7 \%)$ answered "extremely", 22 subjects $(32,4 \%)$ answered "very much", while "enough" was the answer given by $19(27,9 \%)$. 
The two-variable analysis and the check of $x^{2}$ criterion showed significant statistical differences $(a<0,05)$ among the subjects' answers regarding their sex $(p=0,001)$, the years of service in the company $(p=0,000)$ and their position in the company $(\mathrm{p}=0,002)$.

In regard to the answers to the question "Would you like a training needs analysis on mentoring issues to take place before your training?" the results of the one-variable analysis showed the following: 30 subjects $(44,1 \%)$ answered "extremely", 20 subjects $(29,4 \%)$ answered "very much", while "enough" was the answer given by 18 (26,5\%).

The two-variable analysis and the check of $x^{2}$ criterion showed significant statistical differences $(\mathrm{a}<0,05)$ among the subjects' answers regarding their age $(p=0,01)$, the years of service in the company $(p=0,001)$ and their position in the company $(\mathrm{p}=0,000)$.

In regard to the answers to the question "Would you like adult training principles to be applied during your training?" the results of the one-variable analysis showed the following: 30 subjects $(44,1 \%)$ answered "extremely", 25 subjects (36,8\%) answered "very much", while "enough" was the answer given by $13(19,1 \%)$.

The two-variable analysis and the check of $x^{2}$ criterion showed significant statistical differences $(\mathrm{a}<0,05)$ among the subjects' answers regarding their age $(p=0,001)$, the years of service in the company $(p=0,000)$ and their position in the company $(\mathrm{p}=0,002)$.

In regard to the answers to the question "Would you like your training to offer knowledge combined with practical exercises?" the results of the one-variable analysis showed the following: 22 subjects $(32,4 \%)$ answered "extremely", 26 subjects $(38,2 \%)$ answered "very much", while "enough" was the answer given by $20(29,4 \%)$.

The two-variable analysis and the check of $x^{2}$ criterion showed significant statistical differences $(a<0,05)$ among the subjects' answers regarding their age $(p=0,00)$, the years of service in the company $(p=0,000)$ and their position in the company $(\mathrm{p}=0,001)$.

\section{Conclusions}

The research results show that a very high percentage of the subjects find their participation in mentoring processes very useful. More specifically they mention that a mentoring process offers learning opportunities in a safe environment and helps them acquire various skills and competences. Moreover, they are helped in problem solving, while at the same time they develop a system of guidance - support by experienced individuals within the company environment.

The above mentioned opinions, concerning the participation in mentoring processes, are strongly influenced by the subjects' demographic characteristics as sex, age, the years of service and the position in the company.

The research results show that the subjects consider that mentors gain many benefits by their participation in the mentoring process. They support that mentors develop and improve their communication skills, while at the same time their position in the company is strengthened. In the mean time, they gain job satisfaction, a feeling of contributing and offering in the company environment and they have the opportunity to transform their initial thoughts and opinions on the mentoring process.

The above mentioned views are highly influenced by the subjects' demographic characteristics and mainly sex, age, years of service and position in the company. These characteristics mainly influence the opinions on the benefits gained by mentors during their participation in a mentoring process.

The research results also show that the subjects believe that the use of mentoring processes in a company environment contributes significantly in the improvement of company's operations. More specifically, they support that mentoring processes contribute in the achievement of the company's goals, in the growth of equal communication and collaboration relationships among employees, as well as between the executives and the employees of the company. Moreover, it contributes in the viable growth of the company.

The above mentioned views are strongly influenced by the subjects' demographic characteristics and mainly sex, age, years of service and position in the company. These characteristics mainly influence the opinions on the benefits offered by mentoring processes to company's well being.

The research shows that a very high percentage of the subjects consider that their training in mentoring processes is necessary. They wish their training to use a method that combines traditional and long-distance learning. They also wish a training needs analysis to take place systematically before the beginning of a training program. Moreover, they wish that their training is based on the adult learning principles and that it combines theoretical knowledge and practical exercises. 
The above mentioned opinions on the training in mentoring processes are strongly influenced by the subjects' demographic characteristics, such as sex, age, years of service and position in the company.

\section{Discussion}

Given the need to develop a mentoring system in the environment of a company or an organization, it is necessary to train mentors. In order to create an effective mentor training, it is important to consider the following:

* Analyse the participants' training needs before designing the training program

* Determine the main purpose and the goals of the training program

* Determine the thematic sections of the program

* Select the appropriate training techniques and means

* Select the appropriate trainers, that have knowledge on the subject and additionally they have knowledge and experience on adult training

* Select the appropriate evaluation type and model

$\$$ Adopt post-cognitive evaluation processes in the frame of transformative learning.

\section{References}

Allen, T. D., \& Eby, L. T. (2007). Handbook of Mentoring: A multiple Perspective Approach. Malden MA: Blackwell.

Billet, S. (2003). Workplace Mentors: Demands and Benefits. Workplace Learning, 15, (3), 105-113

Broadbent, R., \& Papadopoulos, T. (2009). Community Education and Youth Mentoring: How to Build Good Practice? Australian Journal of Adult Learning, 49, (2), 318-351

Clutterbuck, D. (2004). Everyone Needs a Mentor - Fostering Talent in your Organization. London: Chartered Institute of Personnel and Development.

Cunningham, J. B., \& Eberle, T. (1993). Characteristics of the Mentoring Experience: A Qualitative Study. Personnel Review, 22 (4), 54-66

Clawson, J. (1996). Mentoring in the Information Age. Leadership \& Organization Development Journal, 17 (3), 6-15

Dimitropoulos, E. (2001), Introduction to Scientific Research Methodology, Athens: Ellin. (in Greek)

Equal. (2006). Developmental sympraxis “Tilemahus" Study on Designing \& Organizing a Mentoring System, Consulting Management Training. (in Greek)

Hale, R. ( 2003). How Training can Add Real Value to the Business: Part 2. Industrial and Commercial Training, 35 (2), 49-52

Kefalas, A. (2005). The process of transition or succession, [Online] available: http://www.terry.uga.edu/ akefalas

Kent, T., Dennis, C., \& Tanton, S. (2003). An Evaluation of Mentoring for SME Retailers. International Journal of Retail \& Distribution Management, 31 (8), 440-448

Kvale, S. (1996). Interviews: An Introduction to Qualitative Research Interviewing, London: Sage Publications.

Ragins, B. R., Cotton, J. L., \& Miller J. S. (2000). Marginal Mentoring: The Effects of Type of Mentor, Quality of Relationship, and Program Design on Work and Career Attitudes. Academy of Management Journal, 43, (6), 1177-1194

Robson, C (2002).Real World Research, Oxford: Blackwell.

Siegel, P. (2000). Using Peer Mentors During Periods of Uncertainty. Leadership \& Organization Development Journal, 21 (5), 243-253

Todd, C. (2005). Mentoring. In N. Skinner, A.M. Roche, J. O'Connor, Y. Pollard, \& C. Todd (Eds.), WorkforceDevelopment TIPS (Theory Into Practice Strategies): A Resource Kit for the Alcohol and Other Drugs Field.National Centre for Education and Training on Addiction (NCETA), Flinders University, Adelaide, Australia.

Van Emmerik, H., Baugh, S.G., \& Euwema, M.C. (2005). Who wants to be a mentor? An Examination of Attitudinal, Instrumental, and Social Motivational Components. Career Development International, 10 (4), 310-324 
Table 1. Age distribution

\begin{tabular}{|c|c|c|}
\hline $25-35$ Years Old & 17 & $25,0 \%$ \\
\hline $36-45$ Years Old & 34 & $50,0 \%$ \\
\hline $46-55$ Years Old & 17 & $25,0 \%$ \\
\hline Total & $\mathbf{6 8}$ & $\mathbf{1 0 0} \%$ \\
\hline
\end{tabular}

Table 2. Position distribution

\begin{tabular}{|c|c|c|}
\hline Unit Managers & 34 & $50,0 \%$ \\
\hline Agency Managers & 17 & $25,0 \%$ \\
\hline Insurance Advisors & 17 & $25,0 \%$ \\
\hline Total & $\mathbf{6 8}$ & $\mathbf{1 0 0} \%$ \\
\hline
\end{tabular}

Table 3. Mentoring and learning opportunities provided in a protected environment

\begin{tabular}{|c|c|c|}
\hline Extremely & 19 & $27,9 \%$ \\
\hline Very Much & 17 & $25,0 \%$ \\
\hline Enough \& A Little & 32 & $47,1 \%$ \\
\hline Total & $\mathbf{6 8}$ & $\mathbf{1 0 0} \%$ \\
\hline
\end{tabular}

Table 4. Mentoring and problem solving in the company

\begin{tabular}{|c|c|c|}
\hline Extremely & 14 & $20,6 \%$ \\
\hline Very Much & 32 & $47,1 \%$ \\
\hline Enough \& A Little & 22 & $32,4 \%$ \\
\hline Total & $\mathbf{6 8}$ & $\mathbf{1 0 0} \%$ \\
\hline
\end{tabular}

Table 5. Mentoring and development of a guidance process by an "important other"

\begin{tabular}{|c|c|c|}
\hline Extremely & 17 & $25,0 \%$ \\
\hline Very Much & 28 & $41,2 \%$ \\
\hline Enough & 23 & $33,8 \%$ \\
\hline Total & $\mathbf{6 8}$ & $\mathbf{1 0 0} \%$ \\
\hline
\end{tabular}

Table 6. Development of communication and cooperation skills

\begin{tabular}{|c|c|c|}
\hline Extremely & 40 & $58,8 \%$ \\
\hline Very Much & 14 & $20,6 \%$ \\
\hline Enough & 14 & $20,6 \%$ \\
\hline Total & $\mathbf{6 8}$ & $\mathbf{1 0 0} \%$ \\
\hline
\end{tabular}


Table 7. Development of professional satisfaction

\begin{tabular}{|c|c|c|}
\hline Extremely & 37 & $54,4 \%$ \\
\hline Very Much & 11 & $16,2 \%$ \\
\hline Enough \& A Little & 20 & $29,4 \%$ \\
\hline Total & $\mathbf{6 8}$ & $\mathbf{1 0 0 \%}$ \\
\hline
\end{tabular}

Table 8. Development of transformational learning processes within the frame of the mentoring process

\begin{tabular}{|c|c|c|}
\hline Extremely & 13 & $19,1 \%$ \\
\hline Very Much & 25 & $36,8 \%$ \\
\hline Enough & 30 & $44,1 \%$ \\
\hline Total & $\mathbf{6 8}$ & $\mathbf{1 0 0 \%}$ \\
\hline
\end{tabular}

Table 9. Contribution of mentoring to the best use of the company's human resources

\begin{tabular}{|c|c|c|}
\hline Extremely & 11 & $16,2 \%$ \\
\hline Very Much & 27 & $39,7 \%$ \\
\hline Enough & 30 & $44,1 \%$ \\
\hline Total & $\mathbf{6 8}$ & $\mathbf{1 0 0} \%$ \\
\hline
\end{tabular}

Table 10. Contribution of mentoring to company innovations

\begin{tabular}{|c|c|c|}
\hline Extremely & 17 & $25,0 \%$ \\
\hline Very Much & 28 & $41,2 \%$ \\
\hline Enough & 23 & $33,8 \%$ \\
\hline Total & $\mathbf{6 8}$ & $\mathbf{1 0 0} \%$ \\
\hline
\end{tabular}

Table 11. Contribution of mentoring to the viable development of the company

\begin{tabular}{|c|c|c|}
\hline Extremely & 27 & $39,7 \%$ \\
\hline Very Much & 22 & $32,4 \%$ \\
\hline Enough & 19 & $27,9 \%$ \\
\hline Total & $\mathbf{6 8}$ & $\mathbf{1 0 0 \%}$ \\
\hline
\end{tabular}

Table 12. Necessity of training on mentoring issues

\begin{tabular}{|c|c|c|}
\hline Extremely & 26 & $38,2 \%$ \\
\hline Very Much & 24 & $35,3 \%$ \\
\hline Enough & 18 & $26,5 \%$ \\
\hline Total & $\mathbf{6 8}$ & $\mathbf{1 0 0} \%$ \\
\hline
\end{tabular}




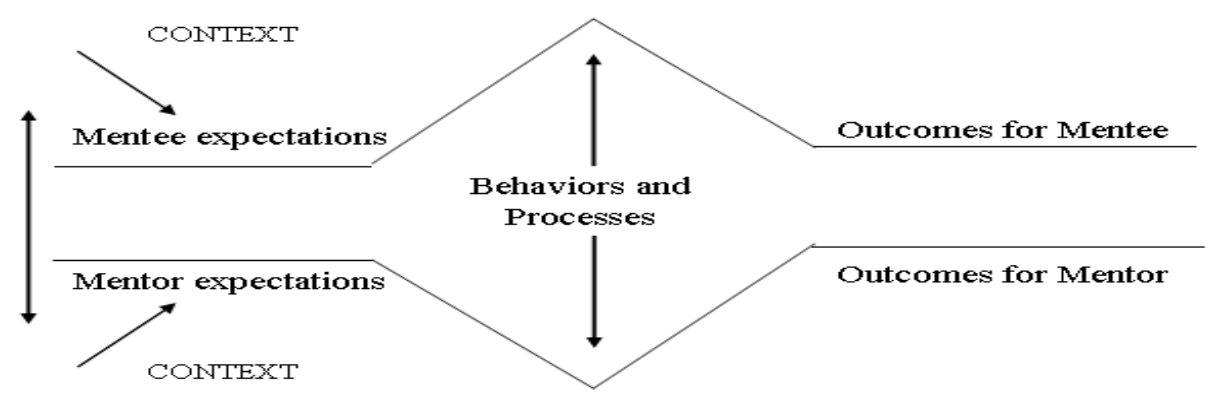

Figure 1. The Context of Mentoring (Clutterbuck, 2004: 15) 